\title{
Influence of Khasi Language on Nasal and Oral Passages in English: A Nasometric Study
}

\author{
Indranil Chatterjee, ${ }^{1}$ Shubhangi Shree Bhatt, ${ }^{1}$ Kavita Kumari, ${ }^{1}$ Divya Raj, ${ }^{1}$ Vidushi Saxena ${ }^{1}$
}

\section{Introduction}

\section{ABSTRACT}

Speech is a overlaid function of respiratory, phonatory, resonatory, articulatory systems. Nasalance can be defined as the relative amounts of oral and nasal acoustic energy in speech done by modification of oral and nasal cativities that is complex activity of the resonator system. Nasometer was developed by Samuel Fletcher, Larry Adams, and Martin McCutcheon at the University is a computer based instrument facilitating accurate analysis of signal yielding nasalance scores. There is no report regarding nasalence score variance in khasi language speakers speaking English.

Materials And Methods

The study aims at analysing and measuring nasalence score in Khasi speakers reading English passages. A total of 5 female subjects were chosen who were native speakers of khasi language and who had exposure of English language since childhoods were selected. Nasometer II Model 6400 (Software version 2.6) of Key Elemetrics Corporation was used. Three standardized passages (Zoo passage, Rainbow passage and nasal sentences) were used for the study.

$\underline{\text { Result }}$

The mean nasalance scores obtained for zoo, rainbow and nasal sentences in female were 19.39 \pm 12.21 SD, $38.13 \pm 14.83$ $S D, 68.33 \pm 15.29 S D$ and $18.26 \pm 3.53$ SD, $33.13 \pm 1.68$ SD, $63.20 \pm 88$ SD respectively. Standard norms show significant differences in nasalance scores obtained for Zoo, Rainbow and Nasal Sentences. Paired t-test was used for comparison among the sentences and computation of data show more significant differences for nasal sentences as compared to zoo and rainbow sentences, that is significant ( $p>0.05)$. Rainbow sentences revealed more nasalance scores than zoo sentences $(p>0.05)$ i.e. level of significance.

\section{Conclusion}

The reported normative Nasalance data can be used by several voice clinicians for assessing resonance quantitively for khasi speakers using austrioasiatic language.

$\underline{\text { Keywords }}$

Nasometry, Nasalance, Khasi, Voice.

$\mathrm{S}$ peech is a overlaid function of respiratory, phonatory, resonatory, articulatory systems that is the audible manifestation of language, whereas language is a set of arbitrary symbols that are socially shared code or conventional system for representation of concepts. ${ }^{1}$ Variation in the harmonics of voice modifies resonance. The resonator system has a complex structure. Supraglottal air gaps act as resonators. These are complex air gaps which are found in the tight area that goes through the larynx, the large opening of the larynx, the wide cavity in the mouth and nasal cavity. Normal speech sound production depends on the ability to rapidly couple and decouple the nasal cavity from the oral cavity. Nasal speech sound require oral nasal coupling and oral sounds require oral nasal decoupling.

The process of coupling and decoupling the oral and nasal cavities for speech is called velopharyngeal valving. This valving is controlled by the elevation

1 - Department of Speech Language and Hearing

Sciences, Ali Yavar Jung National Institute for the Hearing

Handicapped, Eastern Regional Centre, Kolkata

\section{Corresponding author:}

Dr Indranil Chatterjee

email: inchat75@rediffmail.com 
of the velum and constriction of the pharyngeal walls.

Role of velopharyngeal mechanism in speech production: The degree of acoustic coupling occurring between oral and nasal cavities causes variations in velopharyngeal functioning. Movement of velum is essential for distinctions in oral and nasal speech sounds. The two important parameters of articulation are adequate velopharyngeal closure and valving action time. Adequate closure can be achieved by elevation and retraction of soft palate along with constriction of nasopharyngeal walls at the same time. In individuals with short palate the posterior pharyngeal wall may move anteriorly to meet the soft palate as a compensatory gesture activity. ${ }^{2}$

There are basically three patters of velopharyngeal closures that had been described in normal subjects; (1) coronal pattern where closure is primarily by velar elevation, (2) circular pattern (with or without Passavant's ridge), in which medial movement to the velum effects closure, (3) sagittal pattern causing medial movement of the lateral pharyngeal wall and the velum contacting the lateral walls rather than posterior wall effecting the closure. ${ }^{3}$

Five muscles are involved in the velar functions which are levator veli palatine, uvular muscles, tensor veli palatine, palatopharyngeus, and palatoglossus. Elevation of velum is primarily by contraction of the levator veli palatine muscles. ${ }^{2,45}$ Velopharyngeal closure is accomplished by the coordinated movement of all of above structures.

The velopharyngeal closure occurs for speech, pneumatic activities (sucking, blowing, whistling) and non- pneumatic activities (gagging, swallowing, and vomiting). However the degree of closure and position differ in all the above activities; even in different phonemes and with different phonetic environments variations can be seen. ${ }^{3}$ Closure may be adequate for pneumatic activities but insufficient for speech or other pneumatic activities. ${ }^{3}$

Nasalance can be defined as the relative amounts of oral and nasal acoustic energy in speech. Nasalisation refers to the lowering of the velum during the vowels or other consonants. Fletcher and
Frost (1974) first proposed the term nasalance for the measure of velopharyngeal closure during voiced speech in which nasally emitted acoustic energy is compared to the orally emitted energy.

Nasometer was developed by Samuel Fletcher, Larry Adams, and Martin McCutcheon at the University of Alabama, Birmingham. It is a computer based instrument facilitating accurate analysis of signals, yielding nasalance scores.

A numeric ratio of nasal acoustic energy to the sum of nasal plus oral acoustic energy is calculated, multiplied by 100 and expressed as a "nasalance score" that is $(\mathrm{N} /(\mathrm{N}+\mathrm{O})) \times 100=$ Nasalance $)$ and is displayed graphically on the host computer screen in real time.

The output of this instrument provides the user with a score that reflects the relative amount of nasal acoustic energy in a subject's speech. Standardized nasometry scores have been published in several languages such as English; ${ }^{6,7}$ Flemish; ${ }^{8}$ Thai. ${ }^{9}$

The nasalance score is a valid correlate of perceived nasality, ${ }^{10}$ has a high specificity $(86 \%)$, a high sensitivity $(87 \%)$, and a high overall efficiency $(87 \%) .{ }^{11}$ Nasalance score has a limited implication for cross-country or cross language comparison because interpretation for identifying normal and abnormal based on the cut off scores is difficult. Therefore, it should be a supplementary but not a substitute for clinical judgment. ${ }^{12}$

Khasi is an Austroasiatic language spoken primarily in Meghalaya state in India by the Khasi people and also by some population in Assam and Bangladesh. India is a multilingual country. In countries where English is spoken as second or third language there might be different interpretation of Nasalance scores in English passages. From the review it is evident that nasal resonance varies in speech sound of different languages and even in different dialects of same language.

It is well established that differences in nasalance scores occur among different native languages. The frequency of phonemic distribution varies in different languages. The distribution of phonemes is different in different languages; standard passage for each 
language should be developed. The corresponding normative nasalance scores should be computed for each language or regional dialect ${ }^{6}$ because vowels are intentionally nasalized in some languages (e.g., French) and some regional dialects, for instance, English Phonetician often described the vowel in American English dialects as more nasalized then the same vowel in Queen's English. For American English, ${ }^{10}$ Australian English, ${ }^{7}$ German, ${ }^{13}$ Castilian Spanish, ${ }^{13}$ Finnish $^{14}$ and Midwest Japanese ${ }^{15}$ these normative nasalance score have been computed.

The study aimed at analysing the impact of Nasalance on khasi speakers reading English passages to compare the mean Nasalance scores across the passages between native khasi speakers and native English speakers and to compute the differences of mean Nasalance between the passage.

\section{Materials and Methods}

Written consent was taken from all the candidates. A total of 5 native Khasi female speakers in the age range $18-25$ years (mean age 22 years) $(\mathrm{SD}=1.58)$ were enrolled for the study. The participants were selected from AYJNISHD (RC) whose native language is Khasi and use English as their second or third language.

Inclusion criteria ensured that a participant should be a native and speaker of local dialect, who can read English fluently and is willing to participate in the study.

Participant with non-intelligible speech or suffering from organic/non organic voice disorder were not considered as also those who had respiratory difficulties or had been suffering from cough or cold.

\section{Speech tools}

The speech stimuli includes- zoo passage ${ }^{16}$ which excluded nasal consonants in English language, and rainbow passage, ${ }^{17}$ containing $11.5 \%$ nasal consonants in English language. A set of five nasal sentences were taken from the manual of Nasometer II which contained 35\% nasal consonants in English. ${ }^{18}$
Calibrated Nasometer II Model 6400 (software version 2.6) of Key Elemetrics Corporation, connected to a desktop computer model (HCL Pentium 4) was used for measurement of mean nasalance in this study. Nasometer was housed in a quiet room which was partially acoustically treated in the clinic of AYJNISHD(RC).

\section{Procedure}

The subjects were asked to read the standardised passages and then their mean Nasalance scores were analysed. Three trials were taken for each passage. The subjects were instructed to start reading after the recording icon was clicked and care was taken that the subjects do not repeat a syllable once spoken, and also do not add fillers like /umm, or /aa / in between.

The nasometer headpiece was positioned in such a way that the oral and nasal microphones were at equivalent distances from the mouth and nose.

Nasalance is derived by the formula: Nasalance $=$ $\{$ nasal (n)/nasal (n) + oral (o) $\} \times 100\}$

\section{Data compilation}

The data obtained was compiled in Microsoft excel worksheet of Windows version 8.1, mean and standard deviation were calculated and applicable statistics was done.

\section{Statistical analysis}

Analysis was done on SPSS software (version 16.0). Paired t- test was used to compare the mean Nasalance differences between the oral and nasal passages and among the passages.

\section{Results}

The different acoustical filtering used in Nasometer offer significant differences in nasalance scores as it measures sound intensity in a $300 \mathrm{~Hz}$ band around a centre frequency of $500 \mathrm{~Hz}$. Thus most of the acoustic energy measured is associated with vowels, 
Table I: Mean nasalance scores and standard deviation for all native khasi speakers as measured on Nasometer II on nasal passage, rainbow passage, zoo passage

\begin{tabular}{|c|c|c|c|c|c|}
\hline VARIABLE & N & MEAN & S. D & MINIMUM & MAXIMUM \\
\hline NASAL PASSAGE & 5 & 68.33 & 15.29 & 6.93 & 96.852 \\
\hline RAINBOW PASSAGE & 5 & 38.13 & 14.83 & 4.66 & 96.662 \\
\hline ZOO PASSAGE & 5 & 19.39 & 12.21 & 4.4 & 72.13 \\
\hline
\end{tabular}

primarily the first formant of vowels. A study done by Rodger et al. ,1991, 1993 reported nasometer to be sensitive (0.89) and specific (0.95) acting as a diagnostic tool for measuring nasalance with the overall efficiency of $0.87 .{ }^{11}$

Mean nasalance for nasal passage, rainbow passage and zoo passage

All 5 khasi native speaker participants were asked to read passages and the mean nasalance scores were analysed. Mean and standard deviation of mean nasalance scores for nasal passage, rainbow passage, zoo passage were calculated. (Table I)

Nasal Sentences showed higher Nasalance score as compared to Zoo passage and rainbow passage, rainbow passage revealed better scores as compared to zoo passage, zoo passage showed little variance from the norms.

The major differences in nasal and oral vowels are due to the position of soft palate. Jones (1976) defined nasal sounds as those sounds that are produced by closing the oral cavity completely at some point with soft palate held at lowered position so that air stream is free to pass through the nose. Following this definition, in khasi language, there are essentially 4 nasal consonant phonemes i.e. $/ \mathrm{m}, / \mathrm{n} /, / \mathrm{\eta}$. Due to the coupling of the buccal and nasal cavities, the first formant of all nasal vowels is slightly reduced in intensity. Generally speaking, the nasal vowels are in the same articulatory position as the corresponding oral vowels. ${ }^{14}$ Intonation patterns are also varied in khasi speakers. Stress in final syllable is a common feature of Austro-Asiatic family, including Khasi language. ${ }^{19}$

Differences of mean nasalance between the passages

Computation of differences in mean and standard deviation of mean nasalance scores were done between nasal passage and rainbow passage, rainbow

Table II: Mean and standard deviation of mean nasalance score for nasal passage and rainbow passage, rainbow and zoo passage, nasal passage and zoo passage

\begin{tabular}{|c|c|c|c|}
\hline PASSAGE & N & MEAN & SD \\
\hline Nasal passage & 5 & 68.33 & 15.29 \\
\hline Rainbow passage & 5 & 38.13 & 14.83 \\
\hline Diff(1-2) & & 30.2 & 15.06 \\
\hline Rainbow passage & 5 & 38.13 & 14.83 \\
\hline Zoo passage & 5 & 19.39 & 12.21 \\
\hline Diff(1-2) & & 18.74 & 13.52 \\
\hline Nasal passage & 5 & 68.33 & 15.29 \\
\hline Zoo passage & 5 & 19.39 & 12.21 \\
\hline Diff(1-2) & & 48.94 & 13.75 \\
\hline
\end{tabular}


Table III: Comparison of means for nasal passage and rainbow passage, rainbow passage and zoo passage, nasal passage and zoo passage

\begin{tabular}{|c|c|c|c|c|}
\hline PASSAGES & VARIANCES & DF & T- VALUE & PR $>/$ T/ \\
\hline Nasal passage and Rainbow passage & Equal & 4 & 6.039 & $<0.0037$ \\
\hline Rainbow passage and Zoo passage & Equal & 4 & 9.173 & $<0.0007$ \\
\hline Nasal passage and Zoo passage & Equal & 4 & 8.85 & $<0.0009$ \\
\hline
\end{tabular}

passage and zoo passage, nasal passage and zoo passage. (Table II)

The degree of freedom and $t$ value comparison of means for nasal passage and rainbow passage, rainbow passage and zoo passage, nasal passage and zoo passage have been shown in Table III.

The result depicted significant difference in mean Nasalance scores of Nasal Sentences and Zoo passage for all 5 native khasi subjects. Nasal Sentences showed higher Nasalance score as compared to Zoo passage.

The mean of nasal sentences and rainbow passages were calculated to find out the mean Nasalance. Significant differences were found between the nasal sentences and Rainbow passage. Thus, the results indicate higher Nasalance values for nasal Sentences.

The mean of Rainbow passage and Zoo Passage were calculated to find out comparison of mean nasalance. Higher significant difference of Nasalance scores was obtained for Rainbow Passage as compared to the Zoo Passage.

\section{Discussion}

When the comparison of mean Nasalance scores was made between native khasi language speakers and standardised normative scores of native English language speakers, a significant difference was observed for zoo passage (Diff in mean $=7.75$ ), rainbow passage (diff in means $=6.66$ ) and nasal passage (diff in mean $=8.78$ ). This higher nasalance for nasal sentences are evident from Table IV in khasi speakers, also supported by previous findings in other languages by various researchers, ${ }^{3}$ across oral and nasal stimuli using Malayalam, Hindi, Bangla languages.?

Most of the studies done revealed higher nasalance in adult females which can be attributed to higher average pitch levels ${ }^{20}$ and the use of greater pitch variability. Females also use different intonation patterns and voice markers for resonance, loudness, and voice quality in their speech. ${ }^{21}$

Table IV: Mean and standard deviation of Khasi speakers and standard norms across the passage

\begin{tabular}{|c|c|c|c|c|}
\hline & \multicolumn{2}{|c|}{ KHASI SPEAKER } & \multicolumn{2}{c|}{ STANDARD NORMS } \\
\hline PASSAGE & MEAN & SD & MEAN & SD \\
\hline Nasal passage & 68.33 & 15.29 & 59.55 & 6.65 \\
\hline Rainbow passage & 38.13 & 14.83 & 31.47 & 5.63 \\
\hline Zoo passage & 19.39 & 12.21 & 11.25 & 5 \\
\hline
\end{tabular}




\section{Conclusion}

This is a preliminary study on female khasi speakers with small sample size for showing the impact of Nasalance on English language. Thus more number of Meghalayan candidates must be chosen and explored, with the consideration of dialectal variations, for establishing a standardised normative of Nasalance scores for khasi people so that better interpretation and diagnosis of khasi patients can be done. Also gender variations can be better observed by increasing the sample size of subjects and norms can be established for reference purposes. The reported normative Nasalance data can be used by several voice clinicians for assessing resonance quantitatively. The normative scores can be used for assessment of different resonance disorders like cleft lip and palate, motor speech disorder, hearing impairment, functional nasality problems, singing pedagogy.

\section{References}

1. Owens R. Language development: An introduction. Ayyn and Bacon communication sciences and disorders series Pearson education ,8 revised edition, Newyork: Macmillan, Pearson 2012, p. 6

2. Zemlin WR. Speech and Hearing Science, Anatomy and Physiology. 3 edition, Rentice Hall, Englewood Cliffs, New Jersey, Allyn \& Bacon 1988, p. 275

3. Shprintzen RJ, McCall GN, Skolnick ML, Lencione RM. Selective movement of the lateral aspects of the pharyngeal walls during velopharyngeal closure for speech, blowing, and whistling in normals. The Cleft Palate Journal 1975 Jan;12(00):51-8

4. Seikel JA, King DW, Drumright DG. Anatomy and physiology for speech and language, and hearing, 4th ed, Delmar cengage learning, 2009, p.328 5. Kent, R. The Speech Sciences. Edition illustrated San Diego, London: The university of Michigan, Singular Publishing group ,1997,p. 194

5. Seaver EJ, Dalston RM, Leeper HA, Adams LE . A study of nasometric values for normal nasal resonance. Journal of Speech, Language and Hearing Research. 1991 Aug; 34(4):71521

6. Van Doorn J, Purcell A. Nasalance levels in the speech of normal Australian children. The Cleft Palate-Craniofacial Journal 1998 Jul; 35(4):287-92
7. Van Lierde KM, Wuyts FL, De Bodt M, Van Cauwenberge P. Nasometric values for normal nasal resonance in the speech of young Flemish adults. The Cleft Palate-Craniofacial Journal 2001 Mar; 38(2):112-8

8. Prathanee B, Thanaviratananich S, Pongjunyakul A, Rengpatanakij K. Nasalance scores for speech in normal Thai children. Scandinavian Journal of Plastic and Reconstructive Surgery and Hand Surgery 2003 Jan 1; 37(6):351-5

9. Fletcher SG. Cleft palate speech assessment through oral nasal acoustic measures. Communicative disorders related to cleft lip and palate. 1989 ; 246-57

10. Rodger M. Dalston, Gary S. Neiman, Gonzalo GonzalezLanda,. Nasometric Sensitivity and Specificity: A Cross-Dialect and CrossCulture Study. The Cleft Palate-Craniofacial Journal 1993,30(3):285-91

11. Vallino-Napoli LD, Montgomery AA. Examination of the standard deviation of mean nasalance scores in subjects with cleft palate: implications for clinical use. The Cleft PalateCraniofacial Journal 1997 Nov; 34(6):512-9

12. Kalyani M, Sinha A.K., Kumar H, Hota BP, Das L. Influence of Mizo Language on Nasal and Oral Passage In English: A Nasometric Study. Asia Pacific Journal of Research. 2016;1

13. Haapanen ML. Nasalance scores in normal Finnish speech. Folia Phoniatrica et Logopaedica 1991; 43(4):197-203

14. Tachimura T, Mori C, Hirata SI, Wada T. Nasalance score variation in normal adult Japanese speakers of Mid-West Japanese dialect. The Cleft Palate-Craniofacial Journal 2000 Sep; 37(5):463-7

15. Fletcher SG. Contingencies for bioelectronic modification of nasality. Journal of Speech and Hearing Disorders 1972 Aug; 37(3):329-46

16. Fairbanks G. Voice and articulation drillbook. New York: Harper \& Row; 1960

17. Fletcher SG, Sooudi I, Frost SD. Quantitative and graphic analysis of prosthetic treatment for "nasalance" in speech. The Journal of Prosthetic Dentistry. 1974 Sep 1; 32(3):284-91

18. Rabel, Lili.1961. Khasi Language of Assam. Baton Rouge, La: Louisiana State Press

19. Anthea I. Britto, Philip C. Doyle. A Comparison of Habitual and Derived Optimal Voice Fundamental Frequency Values in Normal Young Adult Speakers. Journal of Speech Hearing Disorder 1990; 55(3):476

20. Holmberg EB, Oates J, Dacakis G, Grant C . Phonetograms, aerodynamic measurements, self-evaluations, and auditory perceptual ratings of male-to-female transsexual voice. Journal of Voice 2010 Sep 1; 24(5):511-22.

21. Holmberg EB, Oates J, Dacakis G, Grant C . Phonetograms, aerodynamic measurements, self-evaluations, and auditory perceptual ratings of male-to-female transsexual voice. Journal of Voice 2010 Sep 1; 24(5):511-22. 